2019.Guérin I. Kumar S. Venkatasubramanian G. Relational and reproductive saving: The case of ceremonial expenses in southern India, The Journal of Cultural Economy. https://www.tandfonline.com/doi/full/10.1080/17530350.2019.1583594

\title{
Rethinking saving. Indian ceremonial gifts as relational and reproductive saving ${ }^{\mathbf{1}}$.
}

Isabelle Guérin, IRD-Cessma and French Institute of Pondicherry

G. Venkatasubramanian, French Institute of Pondicherry

Santosh Kumar, French Institute of Pondicherry

19 November 2018

\begin{abstract}
Economic anthropology has long advocated a broader vision of savings than the vision proposed by economists. This article extends this redefinitional effort by examining ceremonial gifts in India and arguing that they are a specific form of savings. Rural households, including those at the bottom of the pyramid, do save, in the sense of storing, accumulating and circulating value. But this takes place via particular forms of mediation that allow savers to forge or maintain social and emotional relations, to keep control over value - what matters in people's lives - and over spaces and their own future. We propose terming these practices relational and reproductive saving, insofar as their main objective is to sustain life across generations. By contrast, trying to encourage saving via bank mediation may dispossess populations of control over their wealth, their socialization, their territories and their time. In an increasingly financialised world of evermore aggressive policies to push people into financial inclusion, the social, symbolic, cultural and political aspects of diverse forms of financial mediation deserve our full attention.
\end{abstract}

\footnotetext{
${ }^{1}$ This research was partially supported by the Institute of Money, Technology and Financial Inclusion. We sincerely thank Ursula Dalinghaus and Mrinalini Tankha for extremely precise and constructive comments that greatly improved the manuscript.
} 
2019.Guérin I. Kumar S. Venkatasubramanian G. Relational and reproductive saving: The case of ceremonial expenses in southern India, The Journal of Cultural Economy. https://www.tandfonline.com/doi/full/10.1080/17530350.2019.1583594

Key words: financial inclusion, saving, India, social relations, emotion, social reproduction

Encouraging the poor to save has long been a concern of governments, activists, philanthropists and bankers. The underlying idea is that they save too little and badly, and that bank mediation would be more rational and efficient than hoarding under the mattress, keeping livestock or any other form of indigenous practice. This concern is greater than ever.

In the absence - or the dismantling - of public health and social security systems, bank saving is expected to help the poor to cope with risk and emergencies, to better plan for the future, whether for life cycle and ritual events, education, housing or economic investments (Collins et al., 2009). The global financial crisis has boosted the rhetoric of financial education, and the underpinning assumption that the poor are financially illiterate and unable to manage their finances (Lazarus 2016). In the global south, where around two billion people are still unbanked, many initiatives are being taken to devise innovative services customised for income irregularity, chronic uncertainty, illiteracy, and spatial and social isolation. Three new features contribute to this: mobile banking, government transfers, which are increasingly mediated by bank accounts, and behavioural economic devices. Behaviorism tells us that lack of self-control, cognitive dissonance, routine or social pressure can lead to low saving (Banerjee and Duflo 2011, p. 183-204). It suggests various ruses and prompts that can help to overcome such biases, including "commitment accounts", mobile phone reminder messages, and basic financial education (Karlan et al. 2014).

The idea that bank saving would necessarily be better, more efficient and more rational for the poor is not however self-evident. It derives form a narrow, distorted vision of the economy that is limited to individual, or conceivably household behaviour, which is believed mainly to be about daily material survival, and the struggle to make ends meet through productive labour. Taking a broad view of saving, meaning any practice of accumulating and circulating value, leads to very different conclusions. 
2019.Guérin I. Kumar S. Venkatasubramanian G. Relational and reproductive saving: The case of ceremonial expenses in southern India, The Journal of Cultural Economy. https://www.tandfonline.com/doi/full/10.1080/17530350.2019.1583594

From the pioneering analyses of Mauss (1950) and Malinowski (1961) on the role of gifts in social and political ties, and Polanyi (1977) on the diversity of exchanges, to more recent works on the social and moral meaning of money (Bloch and Parry 1989, Zelizer 1994) and exchanges (Parry 1989; Berry 1989, Douglas and Isherwood 1980, Guyer 1997), this idea is quite familiar to economic anthropology. Further analysis however is essential into the dynamics of change - and resistance to change - and the current pathways of financialisation and financial inclusion policies.

Our focus here is ceremonial transactions and empirical evidence from rural southern India, but we believe our example illustrates wider trends. Saving policies from above, despite their intentions, had rather disappointing results. Rural households, including those the bottom of the pyramid, do save, in the sense that they store, accumulate and circulate value. But it is via specific forms of mediation and the ceremonial transactions which are a central component, that savers can forge or maintain social and emotional relations, to keep control over value - what matters in people's lives - and over spaces and their own futures. We propose terming these practices relational and reproductive saving. By this we mean forms of saving mediated by specific social and emotional relations, circulating within specific temporalities and spaces. Indigenous hoarding shapes social and emotional interdependencies, delineates spatial boundaries, fits into specific words of meaning and value, link past, present and future generations, and contribute to the social reproduction of households, communities and generations. People keep explicit accounts of contributions and receipts, and switch between debtor and creditor positions across their life cycle, but accounting remains imbued with social and emotional considerations.

By contrast, and in keeping with Peebles' findings (2014), trying to encourage saving through bank mediation may dispossess populations of control over their wealth, their socialization, their territories and their time. Our purpose is not praise indigenous practices, which are shaped by and constitutive of inequalities and hierarchies, but to highlight their worlds of meaning, both on the micro-level of interpersonal and intimate ties, and on the broader level of the sustainability of life across generations (Narotzky and Besnier 2014). 
2019.Guérin I. Kumar S. Venkatasubramanian G. Relational and reproductive saving: The case of ceremonial expenses in southern India, The Journal of Cultural Economy. https://www.tandfonline.com/doi/full/10.1080/17530350.2019.1583594

\section{Relational and Reproductive saving}

The concept of relational and reproductive saving derives from a substantive definition of the economy, in contrast to a formal definition of the economy. A substantive definition considers the economy as a constellation of interpersonal relations, and the relations between individuals and their environment, which take specific forms across time, space and culture (Polanyi 1977). The substantive economy takes shape through a wide range of processes, practices and behaviors that people deploy on a daily basis, not only to make a living but also to give meaning to their life. People work, produce, borrow, save, exchange, give away and redistribute on the basis of both material constraints and also the values of their groups of belonging, which can be multiple and conflicting. These in turn are based on a wide set of rights and obligations, which people can both adhere to and try to break away from. Likewise, people think and act on the basis of social and emotional relations and expectations. They aren't just trying to meet their basic needs, but aspiring to respect, dignity, emotional care and affection. Economic transactions are thus fundamentally social and emotional interactions, which aim at "creating, maintaining, symbolizing, and transforming meaningful social relations" (Zelizer 2012: 149). These however are not isolated or restricted to interpersonal ties. Social interactions are shaped by and constitutive of broader structural forces, which combine norms, values, power relations and resource distribution. The relational economy is thus an economy of social reproduction. It aims to sustain life across generations (Narotzky and Besnier 2014). This does not exclude logics of accumulation, market exchange and individual calculations, but they are subordinate to the logic and constraints of social reproduction.

Our argument is that relational saving plays a crucial role in household reproduction, both economically (helping to accumulate lump sums, smooth expenses and income over time) and socially (helping to maintain or possibly strengthen family or clan status and reputation). A number of ethnographies on various sorts of goods such as livestock, gold, grains, clothing can be re-read though this angle (Shipton 2007; Guyer 1997; Morvant-Roux and Servet 2014; Saiag 2013). They all share a high symbolic and material value, a reserve or exchange function, and the interplay of hoarding and circulation to cope 
2019.Guérin I. Kumar S. Venkatasubramanian G. Relational and reproductive saving: The case of ceremonial expenses in southern India, The Journal of Cultural Economy. https://www.tandfonline.com/doi/full/10.1080/17530350.2019.1583594

with uncertainty and maintain bonds, asserting respectability and prestige. We believe that specific forms of expenses, and notably ceremonial transactions, take this logic even further since they only take on meaning through circulation. Labelling them as saving requires a specific conceptualisation of saving, however.

As we shall see throughout this paper, ceremonial saving does not take place on the individual level but through larger, variable units based on events and circumstances. This is sometimes the household, sometimes the lineage or a fraction of it (given that definitions of household and lineage are malleable and in constant reconfiguration). Saving is not limited to residual, unspent income: it operates over the long term, but mostly on a generational level (and not only the life cycle of one particular person). It primarily works towards various interwoven objectives. The material and immaterial are not separate, but co-constitutive. It is thus a 'multi-purpose' saving, to echo the Polanyian idea of 'multiple-purpose money'. Economic theory often distinguishes between precautionary saving (to smooth consumption or cope with negative income shocks), and investment saving (to maximize expected future consumption through the gradual accumulation of small sums). Most economic studies have considered the poor to be in essence incapable of making long-term considerations, since short-term survival is their primary concern $^{2}$. It is assumed that precautionary saving would be the most common form of saving, with investment saving inexistent. As we shall see here, not only is material insecurity fully compatible with long-term projection, but this itself is closely linked to the past: relational saving goes cross generations. Last but not least, relational saving entails a specific relation to space. It is not restricted to the microlocal - the mattress, the room, the garden, house, the neighborhood. It is not de-territorialized like most bank saving, but anchored in particular spaces that are inseparable, here too, from the social reproduction of the group of belonging.

Economists do not ignore ceremonial expenditure. Banerjee and Duflo for instance quantify their importance, and estimate that they account for $14 \%$ of families' annual expenses on average in India

\footnotetext{
${ }^{2}$ See for instance Rosenzweig (2001), that many papers in economics refer to.
} 
2019.Guérin I. Kumar S. Venkatasubramanian G. Relational and reproductive saving: The case of ceremonial expenses in southern India, The Journal of Cultural Economy. https://www.tandfonline.com/doi/full/10.1080/17530350.2019.1583594

(Banerjee and Duflo 2011: 37). But they consider them superfluous expenses, intended to prevent 'losing face' and moreover as 'distraction' and enjoyment of the present moment in the absence of uncertain, risky longer-term projects (ibid: 36-38). This type of judgment shows a total misunderstanding of local social and economic dynamics. Other economists have studied the role of informal transfers (but not ceremonies per se) in depth and have analysed them mostly as forms of insurance (Morduch 1999). But as far as we can tell, the economic (and social) function of ceremonies remain a blind spot $^{3}$.

\section{Context}

This paper's findings are part of a of long-term research program on labour and finance in two districts (Villipuram and Cuddalore) of north and coastal rural Tamil Nadu, southern India. This particular research project allowed us to explore in more detail the use of a recent financial inclusion program which has involved channeling social payments through bank accounts in order to promote saving deposits. Ethnography was our main method, through the observation of around twenty ceremonies. We attended the entire process for five of those, from the preparations, which involve lively debates among family members and subtle calculations to determine the scale of the events, to post-ceremonial remarks, both within the family (with heated debates on the generosity or conversely the selfishness of the guests) and the neighbourhood (here with endless judgments on the greatness - or the smallness - of the event). Discussions about notebooks - a backbone of ceremonial savings as we shall see below - were also key. We asked the organizers to comment on each transaction, and they spontaneously described the social and emotional nature of the relationships underlying the transactions, from feelings of gratitude, pride and satisfaction, to humiliation, disappointment and bitterness. Some of the results of a separate longitudinal household survey from the same region were also used to confirm the negligible amount of bank savings ${ }^{4}$.

\footnotetext{
${ }^{3}$ Concerning India, Rao's study (Rao 2010) is an exception, but it focuses on festivals, whose logic differs from family ceremonies since their rules are played out at the community level.

4405 households surveyed in 2010 and again in 2016-2017 in the Neemsis survey (https://neemsis.hypotheses.org/). Households distributed across ten villages in northern coastal rural Tamil Nadu
} 
2019.Guérin I. Kumar S. Venkatasubramanian G. Relational and reproductive saving: The case of ceremonial expenses in southern India, The Journal of Cultural Economy. https://www.tandfonline.com/doi/full/10.1080/17530350.2019.1583594

The region has undergone significant transformations over the last decades, with the growing importance of non-farm labour through migration, mostly short-term migration to nearby towns, the partial adoption of urban lifestyles and the politicization of low castes. This in turn has led to a certain reconfiguration of power relations, albeit with ongoing caste-based differentiations and hierarchies, be it in terms of employment, landownership or rituals, as well as the persistence of strong gender inequalities. As in many other contexts, saving among the poor has long been raising public interest. Many reports from the British period emphasized the inability of the poor to plan the future, their improvidence and extravagance. Debt was seen as their only financial strategy (Pouchepadass 1980). In the region we studied, Christian missionaries have attempted to create saving groups since the 1930s, but without much success (Cederlof 1997). Since independence and up to the contemporary period, there has been a succession of many policies and programmes. Saving deposits were often a secondary objective (priority was given to modernising agriculture and diversifying rural economies) and limited to well-off farmers (through rural cooperatives). As the poor were thought to lack any potential to save, the focus has been on 'productive' credit, with the idea of helping them generate income and acquire assets. In the 1990s the Indian microcredit model of Self-Help-Groups (SHG) emerged. It was based on the 'saving first' principle. Groups are made eligible for microcredit after proving their ability to marshal their members and to circulate savings within the group. Although the SHG program became the biggest women's microcredit program worldwide over two decades (at its peak in 2009, 1.6 million groups were being financed, mostly consisting of women's groups), the savings element has been much less of a success. Most women in fact only save the minimum necessary to be eligible for credit.

A series of financial inclusion programs has strengthened the focus on saving since 2004. Two main measures were intended to incentivise saving through bank deposits. The first was to bring banking services to people's doorsteps through 'business correspondents' (non-bank agents who travel from village to village) and new technologies for digital transactions in villages. The second measure was

along the border of the two districts, Villupuram and Cuddalore. Households and villages were randomly selected, using a stratified sample based on caste and location in terms of water availability and distance to town. 
2019.Guérin I. Kumar S. Venkatasubramanian G. Relational and reproductive saving: The case of ceremonial expenses in southern India, The Journal of Cultural Economy. https://www.tandfonline.com/doi/full/10.1080/17530350.2019.1583594

direct payment of social transfers (which can be a high share of poor Indian household incomes) into bank accounts. In Tamil Nadu, households no longer have a choice. Eligibility for welfare schemes requires a bank account into which social transfers are transferred. In 2013, a Reserve Bank of India Report concluded that "developing a culture of saving among large segments of rural population [...] is a pillar of the financial inclusion agenda" (RBI, 2013: 3).

In 2016, twelve years after the launch of the first financial inclusion public program, and four years on from current prime minister Narendra Modi's announcement of the plan to "eradicate financial untouchability"5, the 'culture of saving' Indian policy makers were seeking has yet to emerge. Bancarisation has made enormous progress. As of 21.9.2016, 246 million accounts had been opened, of which 151 million were classified as rural $^{6}$. In our field area, bank account take-up was already widespread in 2010, with $91.2 \%$ households having a bank account. By 2016, take-up had risen to an even higher 97.5\% (Guérin et al. 2017). Achievements in terms of saving deposits however are less convincing. The median amount is unchanged (around 600 INR) and the average amount had even decreased (from 4470 INR to 2043 INR). Most bank accounts are in fact 'dormant' and mostly used as a conduit for social transfers.

In villages, we were frequently told that bank deposits were "useless". People were clear that informal saving made more sense, both socially and financially. Gold, in particular, meets a much higher demand for storing value than keeping money in a bank account. As in 2010, gold is still the most important form of saving. Most households own gold (95.7\%) at an average weight of 52.2 grams, for an average value of 155,653 INR (76 times more than the average value of bank deposits).

Mistrust is a first explanation, which closely but not exclusively related to unreliability owing to poor fingerprint authentications, bad internet connections, low battery charges, machine failures and poor maintenance, inadequate information transfers between administrative services and banks, limited

\footnotetext{
${ }^{5}$ Quoted in Hindu Business Line, 2014.

${ }^{6}$ Data available on http://pmjdy.gov.in/account.
} 
2019.Guérin I. Kumar S. Venkatasubramanian G. Relational and reproductive saving: The case of ceremonial expenses in southern India, The Journal of Cultural Economy. https://www.tandfonline.com/doi/full/10.1080/17530350.2019.1583594

amounts, insufficient cash flows or even absent business correspondents. Such distrust is reinforced by the real or imaginary misuse of bank information, for instance to pinpoint 'below poverty line' households (people fear that saving deposits may make them lose this administrative status and their eligibility to numerous welfare schemes). Gender and caste barriers are another obstacle, both in terms of the bank and correspondents. Bankers are by and large neither equipped nor willing to deal with poor rural women and many women feel denigrated, especially when they are Dalits.

A second, closely related factor is the 'comparative advantage' of prevailing informal saving practices, to quote the economists. We have discussed elsewhere the social, cultural and political factors for the persistence of informal saving, particularly in gold (Guérin et al. 2018, Goedecke et al. 2018; see also Joseph 2018). It is less common to consider ceremonies as saving, as we propose here.

\section{Ceremonies as Relational and Reproductive Saving}

In Tamil Nadu as elsewhere in India, social and religious rituals are an essential part of social, cultural and political, but also economic life. Far from being a residue of 'tradition', rituals are constantly renewed and reinvented, combining both contextual specificities and homogenisation processes. It is an ongoing question as to whether rituals and ceremonies reproduce inequalities and hierarchies, or conversely open up spaces of resistance and political contestation. In rural Tamil Nadu, the reappropriation of rituals, whether in terms of meaning or funding, is a powerful tool for asserting individual and collective identities, especially among Dalits (De Neve 2000, Picherit 2018). At the same time, some dominant group rituals continue to spread. This is the case of the dowry, a Brahmin practice which many social groups have adopted in recent years, and around the 1960s in Tamil Nadu (Kapadia 1996). The prevalence of the dowry is often presented, perceived and upheld, as pre-mortem compensation for nonaccess to inheritance for girls, including by the women themselves. Although generous dowries certainly boost the social standing of households, clans and the women themselves in their community (much less than it being material protection for the women, as it is most often appropriated by in-laws), it is obviously a symptom of - and a powerful tool of - entrenched patriarchy. 
2019.Guérin I. Kumar S. Venkatasubramanian G. Relational and reproductive saving: The case of ceremonial expenses in southern India, The Journal of Cultural Economy. https://www.tandfonline.com/doi/full/10.1080/17530350.2019.1583594

In the context of our study, among Dalits and at the household level ${ }^{7}$, the most common ceremonies include children's weddings, girls' puberty, funerals and more recently, first birthdays (mostly for boys) and housewarmings. Weddings are the most important events in terms of amount, which vary according to social group. For Dalits, typical amounts in the region now range from three to six lacks $(300,000$ to $600,000 \mathrm{INR}$ ), which on average amounts to four to eight years of household income. These amounts have risen considerably over recent decades and include the cost of the cerebration, gifts to close relatives and the dowry.

Various tools, techniques and objects situate and mediate ceremonial expenses and transactions as savings, from mundane objects to precious goods such as gold and human embodied memory. Families usually keep one notebook per event (see photographs below as examples), with a list of the givers specifying their names, location and the amount of their gift, which can be in cash or in kind, mostly gold, clothes, vessels and food ${ }^{8}$. Gifts in kind are restricted to relatives (exceptionally close friends may give gold). The example below is an extract from a notebook for a housewarming. The book lists 283 givers, of which 25 are given below.

Photograph 1 to be inserted around here.

Photograph 2 to be inserted around here.

As for the givers, some keep written accounts but many rely on their memory to record their gifts. Usually a member of each family, most often a woman, is in charge of remembering the family record, which can be traced back over several generations. In this, one finds here a number of techniques close to those Yates identified (1966) for constructing an oral memory. The women keep precise images of people, events and locations. Whenever they meet someone from a particular family, the memory of the transaction comes up in their mind. Any discussion on this particular family is also an opportunity to remember. The active cultivation of memory frames the generational scope of saving. When transactions

\footnotetext{
${ }^{7}$ Religious festivals related to temples and specific divinities are another crucial component of rituals.

${ }^{8} \mathrm{We}$ refer here to the gifts offered by the guests, and not the dowry, which includes a specific list of items.
} 
2019.Guérin I. Kumar S. Venkatasubramanian G. Relational and reproductive saving: The case of ceremonial expenses in southern India, The Journal of Cultural Economy. https://www.tandfonline.com/doi/full/10.1080/17530350.2019.1583594

cause tension or conflict, as is often the case as we shall see below, recalling them repeatedly also helps to fix the memory. It may happen that the giver keeps a written trace of his or her own gifts (a note on a calendar, a chalk mark on the wall). Organisers also often tick off lines on their notebook once the gift has been given back. Memory and mnemonic devices mediate embodied records of accounts of these ceremonies over time.

Very little attention has unfortunately been paid to accounting practices among the poor, as if poverty, by essence, were incompatible with accounting (Dowdy 2014). And yet these events, and the notebooks and the memory that go with them, play a key role in family calculations, long-term planning and saving strategies, for various reasons. First of all, these events are concrete opportunities to display and make visible the status (mariyatai) of the family. Ceremonies, insofar as they gather the whole set of relations of individuals and their families, and insofar as they are in great part funded by this same set of relations, express one's mariyatai and contribute to building it. The scale of the ceremony is evaluated in terms of guest numbers, their 'quality', the quality of food provided, and the gifts received: all this aims at maintaining, possibly uplifting or at least not downgrading the organisers' mariyatai (and that of their respective kin). Far from being simple, depersonalized and individual numbers like a saving account balance sheet, ceremonies reflect, crystalize and update the social wealth of a group and its control over specific territories, which are assessed both in terms of the size of the local population in attendance, and the capacity to attract outsiders.

The scale of the ceremony mostly depends on two criteria. The scale of ceremonies recently organised within the close circle (kinship and neighbourhood) is a first benchmark. Doing less amounts to a downgrade in terms of honor. Doing better, even very slightly, is usually what is expected. At the same time, one is supposed to organise an event within one's financial and human resources. Human resources are needed to help with the preparation of the food, service and cleaning - the events usually bring together several hundred guests who must be welcomed, fed and sometimes accommodated. Financial resources depend on available savings (has the family been able to accumulate gold, possibly land that can be offered, sold or pledged?), borrowing capacities (how much can the family borrow and what is 
2019.Guérin I. Kumar S. Venkatasubramanian G. Relational and reproductive saving: The case of ceremonial expenses in southern India, The Journal of Cultural Economy. https://www.tandfonline.com/doi/full/10.1080/17530350.2019.1583594

its creditworthiness in the eyes of potential creditors?). Last but not least, how much can be expected from the guests in gifts (moi)? The moi pannam (the sum of donations offered at the time of the event) most often represents a substantial proportion of ceremony expenses, or even more. In fact, asides from daughters' weddings which always lead to a 'loss' due to the dowry, every ceremony is expected to lead to a surplus, a 'profit', as we were often told (the English term is frequently used). In fact, the moi pannam is the 'knot' of the event, its pillar. In other words, ceremonies are a kind of bet on the generosity of their social circle (both in money and in time), which in turn depends on the obligations the organisers have accrued over the years. For funerals, guests are expected to provide rice and cooking items, which should then be returned in a timely fashion.

Given the social importance of ceremonies and the amounts they involve, but also their place in a long chain of rights and obligations and financial transactions that compress or extend space and time, they are thus at the core of family calculations. As we were told once, each event "is a link to the past, the present and the future". It is an opportunity to show "the strength of your family and relatives" as we were also told, but the strength in question is a process: each event updates prior relations and prefigures upcoming relations. Calculations and evaluations take place before the event and help the organisers to plan ahead. Calculations and evaluations also occur after the event: each gift (and his/her donator) is evaluated, valued, and judged (in short, is it in line with expectations?).

To return to saving, the wide set of debts and entitlements that are contracted through ceremonies is thus a crucial aspect of a given household's financial position. Depending upon their position within their life-cycle, but also the nature of their social network and particular circumstances, households are net debtors or net creditors. Using the words of Rutherford (2001), some households "save up" (they slowly accumulate through regular donations and then organise their own event, see fig. 1 below), "save down" (they organise an event and then pay back slowly) or "save through" (a mix of the two).

Graph 1 below shows a household which has regularly saved since marriage in 2005 by making regular donations to its social circle, and getting this partly back for the daughter's puberty ceremony. 
2019.Guérin I. Kumar S. Venkatasubramanian G. Relational and reproductive saving: The case of ceremonial expenses in southern India, The Journal of Cultural Economy. https://www.tandfonline.com/doi/full/10.1080/17530350.2019.1583594

Graph 1 to be inserted around here.

Parents with unmarried daughters most often "save down". Sivakumar" is a typical example. He first organised the puberty ceremony of his daughter. This allowed him to collect 13 sovereigns ${ }^{10}$ of gold which he put aside for her future marriage. He may have to pledge them regularly for various needs and hope he won't lose them. He will "pay back" (this is the term used) in around ten years, roughly at the time of his daughter's marriage for which he will go back into debt for many years.

\section{Calculations and equivalences}

There is no strict equivalency between savings given and received, and gifts and counter-gifts. The amounts result from subtle calculations. Here, one finds the various modes of economic exchange reciprocity, redistribution, sometimes market logic - but these hardly operate in isolation from social relations, both for the group's social reproduction (the size and definition of which is permanently negotiated) and on the level of individual, specific relations. Exchanges are not rule-based only, but contingent upon relational practices in context.

\section{- Reciprocity}

For friends, colleagues and distant relatives, amounts (in cash) or weight (in gold) are systematically compared with how much has previously been given and received: in brief, how much do I owe the organiser at the time of ceremony? Reciprocity is both specific (calculated for one particular event) and global (on the scale of the entire chain of exchanges between families). While calculations distinguish between various forms of ceremonies - one may not give the same amount for a housewarming than a marriage - the total value of exchanges between two families can be taken into account. For instance, someone who has had several children get married may give more to a housewarming ceremony organised by someone who has few or no children. In the same vein, calculations may include other

\footnotetext{
${ }^{9}$ All names have been changed to ensure anonymity.

${ }^{10}$ One sovereign is equal to around 8 grams of gold. It is the most common unit of measurement of gold in the region.
} 
2019.Guérin I. Kumar S. Venkatasubramanian G. Relational and reproductive saving: The case of ceremonial expenses in southern India, The Journal of Cultural Economy. https://www.tandfonline.com/doi/full/10.1080/17530350.2019.1583594

forms of exchanges with the organiser besides ceremonies, such as loans or favours received or offered. Such compensation is limited however, because it is not made public, while ceremonial reciprocity must be public.

\section{- Redistribution}

Transactions with close relatives relate to specific obligations. Within the kinship for instance, elder brothers and maternal uncles are expected to take on important responsibilities in the marriages of their younger brothers or sisters and nieces. Patrons (big landowners, employers, possibly local politicians) are also expected to help significantly (through gifts or loans), although this seems to be on the decline. In return, kinship and working relations are not something people have but something they $d o$, and ceremonies are instrumental in this process. Maternal uncles gain their status of maternal uncles because they organise their nieces' marriages. Patrons gain their status of patron (or used to) partly because they help their workers or voters to hold their ceremonies.

\section{- Social reproduction}

As mentioned above, the status of the family is the defining issue. Reputations are formed and reformed at the time of ceremonies, but through a long-term process, since each event gets a meaning only by recalling past events and by projecting future ones, over various timeframes. For instance, a puberty ceremony is a preview of a marriage. Comparing marriages of daughters, mothers and grandmothers is used to assess or deny the upward mobility of the lineage.

\section{- Social and emotional transactions}

Far beyond strict and fixed rules of rights and obligations, all transactions are first and foremost social relations, whether based on solidarity or hierarchy. Quantity takes on meaning only if associated with quality. Closeness is hardly a given, but facilitated by various forms of social ties such as kinship, neighbourhood, work or politics. But their intensity is based on emotional ties such as affection, friendship or love. Gifts are used to express the intensity of the bonds and the willingness to continue 
2019.Guérin I. Kumar S. Venkatasubramanian G. Relational and reproductive saving: The case of ceremonial expenses in southern India, The Journal of Cultural Economy. https://www.tandfonline.com/doi/full/10.1080/17530350.2019.1583594

the relationship. Giving much more (or less) than what was given in the past is a clear signal that the relation should continue (or stop). One person may give more out of gratitude or pity; another may give less out of vengeance or humiliation. In the same vein, obligations are not dictated by tradition but constantly negotiated. Couples who left the extended family to live in their own house are often accused of selfishness and are a typical case: they must show solidarity and are expected to give much more than if they had remained with the group. The same applies for hierarchical relations. The social positioning between giver and receiver certainly depends on social belonging and hierarchical ties based on class, caste, kinship and gender, but also on specific relations and aspirations. Those wanting to show their superiority must give more. Comparison is crucial here, since giving less than people from the same rank would be degrading. Comparisons are made at many levels, between the male and the female branch of one particular family, between sisters-in-law or between sisters, neighbours or colleagues, dominant families within a neighbourhood, close neighbourhoods or castes. Women's status among their in-laws is in greatly shaped by how much was given for their marriage (the famous dowry), as are rivalries between women, although this doesn't rule out solidarity.

In the same vein, receivers evaluate gifts according to diverse criteria. The financial value of the gift matters, but so too does the human and moral support given throughout the event, from the first preparations to cleaning-up. As we were often told, there are those who come, eat, and leave, and those who stay from morning to evening, always ready to help. There are those who approve, encourage and congratulate, and those who disapprove, complain and criticize. The meaning of each transaction is affected by pre-existing social relations, which in turn may be strengthened or modified. In other words, transactions make the relations. Relations are both constitutive of and shaped by ceremonial transactions. As Zelizer (1994) has shown at length elsewhere, money and social ties are closely interwoven. Even if people regularly complain about the fact that ceremonies are now a "business" - and indeed the sums of money involved are astonishing, the way people experience, understand and comment on these events clearly shows the pre-eminence of social relations, as we shall see in the next section. 
2019.Guérin I. Kumar S. Venkatasubramanian G. Relational and reproductive saving: The case of ceremonial expenses in southern India, The Journal of Cultural Economy. https://www.tandfonline.com/doi/full/10.1080/17530350.2019.1583594

Because there is no strict equivalency, amounts received may differ widely from expectations. As mentioned earlier, people largely plan the scope and the cost of a ceremony by taking into account how much they expect as gifts. Calculations always have an element of uncertainty (guests may give less than expected) and risk (an important gift may never be reciprocated). And since exchanges take place in an interrupted chain of gifts and counter-gifts, disappointments (guests have given less than expected) may be counterbalanced by the hope of future reciprocity. Events unrelated to the life cycle, such as birthdays or housewarmings, can be used to compensate for 'losses' or even cash flow problems. We encountered a number of households who felt they had been cheated and organised a birthday or a housewarming with the hope of getting back their dues. In theory, transactions take place in distinct exchange spheres - a gift for a wedding should be reciprocated for another wedding - and are thus non fungible. In practice however, getting back one's due (or not plunging in over-indebtedness) is a constant concern and this leads to a relative fungibility of exchanges and a certain form of market logic (on this see also Cattelino 2009).

In the same vein, organising ceremonies with the idea of paying back a debt is rather frequent. Graph 2 illustrates such a calculation with a woman called Parvathi, and her husband, heavily indebted for the renovation of their house. They organised a housewarming to pay off part of the debt. Gifts to others in the past amounted to around 136000 INR, while they received 69300. This made them "net creditors" for 66700 INR, distributed among various circles (distant relatives, close relatives, friends and colleagues). They were disappointed, but hope to get more for the marriage of their son in the future. Our graph gives precise figures while Parvathi's calculations are rough estimates based on mental arithmetic. It is interesting to note however that in all our case studies, both estimations were very similar.

Graph 2 to be inserted around here. 
2019.Guérin I. Kumar S. Venkatasubramanian G. Relational and reproductive saving: The case of ceremonial expenses in southern India, The Journal of Cultural Economy. https://www.tandfonline.com/doi/full/10.1080/17530350.2019.1583594

\section{Emotional calculations}

Ceremonial expenses involve subtle financial calculations, which are often very precise and on various scales, whether it be short term relations with colleagues or decisions for children's futures. Future plans and forthcoming events are thus crucial. People planning to organise an event may be more generous on purpose in the preceding years. Many women clearly explained that they 'save' in that way during the years prior to their own event. Guests who know they won't have further opportunities to meet the organizer may give such that accounts are cleared, preventing one party from being a net debtor. Although financial calculations are key, it would be misleading to stop here. Emotional aspects are also crucial, and a detailed example is certainly the best way to illustrate the intermingling of financial and emotional aspects.

Sivaselvi and her husband Kumaresan organised a housewarming in 2014. Around 750 people came, most in families, and in total, the organisers received 283 gifts (around one gift per family). The event cost them around $150000 \mathrm{INR}^{11}$ (mostly food and transport, which was taken care of for distant guests). They received 192365 INR as gift (moi panam), which means a "surplus" of around 40000 INR, that Sivaselvi used to pay off past debts. Gifts in cash ranged from 50 to 3000 INR. Gifts in gold ranged from a quarter of sovereign to 2.5 sovereigns (from around 5500 to 55000 INR). The number and profile of the guests was a great source of satisfaction: most of the neigbhours came, and many from outside and sometime long distances, revealing the territorial spread of the family. In terms of gifts however, Sivaselvi explains bitterly that she was expecting a surplus of twice more.

Out of the 283 givers, 60 belong to the circle of her husband (friends and colleagues). She is not aware of the prior transactions between them and her husband, and thus she is not able to appreciate their contribution. In the list, 141 givers are marked with a cross: she considers that for them, accounts are closed: in a few cases, these are elderly people who won't have any other ceremonies in the future; in most cases, they are people she doesn't want to deal with in the future because they gave too little. For

\footnotetext{
${ }^{11}$ This represents roughly the annual household income.
} 
2019.Guérin I. Kumar S. Venkatasubramanian G. Relational and reproductive saving: The case of ceremonial expenses in southern India, The Journal of Cultural Economy. https://www.tandfonline.com/doi/full/10.1080/17530350.2019.1583594

the remainder (82), accounts are still 'open' and in most cases she considers that she received less than what she gave in the past, but in a number of cases for good reasons. First, this was a housewarming ceremony: this is not a systematic practice, many don't do it, thus there are no strict rules for gifts (as observed in marriages and puberty ceremonies for instance) and those who don't organise housewarmings themselves are tempted to give little, since there may not be reciprocity. And when they do give, they may give less in the future, including for more "formal" events such as puberty ceremonies or marriages, bearing in mind the objective of balanced reciprocity. In the case of Sivaselvi, she has two children, as yet unmarried. Her 24-year-old son holds a master degree. He will get married soon and people know. Her daughter, 21 years old, is also under marriageable age but may not do so since she is physically handicapped (she uses a wheelchair). Amounts given at the time of the housewarming take into account these two (potential) forthcoming events. For instance, Rajendran gave 500 INR, while Sivaselvi gave him 3000 INR a few years back for a pilgrimage. Pazhani gave her 1001 INR, while Sivaselvi gave her 1000 INR five years back for a marriage and 500 INR two years back for a puberty ceremony. In both cases, Sivaselvi is expecting them to give some sort of balance at the time of the marriage of her children. But the fact that her daughter may not get married is a source of concern. Notwithstanding the future of her daughter, which is of course the most worrying issue, Sivaselvi may lose money. But she thinks that her closest relations are aware of this and may compensate by giving more for her son's marriage.

Coming back to the housewarming, the greatest disappointments were her three brothers-in-law. Emotion is not additive, but a full part of her accounting technique and memory device. She was expecting something like 35 000/40 000 INR (in gold), in line with what she gave them in the past (the three brothers live together in the same house and had a housewarming four years back). They gave only one sovereign of gold (with costs around 22000 at the time of the ceremony) and she experienced this as an insult. On her own side by contrast, her brothers have been rather generous: her elder brother gave 2.5 sovereign and the younger 1 sovereign. Her older brother gave much more than what he had received from her in the past. Not only is he her brother, which entails specific obligations, but his gesture is also 
2019.Guérin I. Kumar S. Venkatasubramanian G. Relational and reproductive saving: The case of ceremonial expenses in southern India, The Journal of Cultural Economy. https://www.tandfonline.com/doi/full/10.1080/17530350.2019.1583594

in line with a forthcoming event: their respective children (her son and his daughter) will get married together (following the rule of cross-cousin marriage, widespread in Tamil Nadu). The generosity of her two brothers (although one of them, the younger one, is "economically down" as she says) also results from a deliberate bid to do "better" than her brothers-in-law. As often, ceremonies are an opportunity for comparison and competition between lineages.

Some guests have given very little, but she knows their difficulties and she even feels "pity" for them. Hence this lady - Parvathy - who gave 200 INR, while Sivaselvi had given her 1000 INR fifteen years back (daughter's marriage), and 500 eight years back (housewarming); Sivaselvi tells us that Parvathy is very poor, she is a widow, she has no income and depends on her son. He came and gave the $200 \mathrm{INR}$, and he may not have the memory of past exchanges. Another good friend, Rose, gave 101 INR, while Sivaselvi had given her 500 INR on various occasions over the last twenty years. But here too she feels more compassion than resentment. Rose's husband is physically challenged, and Rose was there from morning to evening to help her out on the day of the housewarming.

These various examples show that moi (gifts) take place in complicated webs of debt which combine obligations and entitlements, reciprocity, feelings, sentiments and emotions such as humiliation, jealousy, empathy, compassion and solidarity. Relational and reproductive saving generate, maintain and reconfigure affective ties between individuals, households, communities, generations, which are themselves set within specific temporalities - the meaning of each transaction is shaped by prior and forthcoming relations - and territories, since community boundaries are closely related to spatial boundaries. Calculations not only reflect, but make and remake affective ties, temporalities and space.

\section{Conclusion}

Jane Guyer's seminal paper (1997) on the difficulties of dialogue between anthropology and economics, lists the various sources of tension and contradictions between the two disciplines, starting with value and wealth, but also units of analysis and temporalities, and ultimately modes of calculation and rationality. Is value a fixed, exogenous and measurable unit, or is it the result of a permanent process 
2019.Guérin I. Kumar S. Venkatasubramanian G. Relational and reproductive saving: The case of ceremonial expenses in southern India, The Journal of Cultural Economy. https://www.tandfonline.com/doi/full/10.1080/17530350.2019.1583594

(valuation versus value), consisting of material goods, including cash, and services, but also social and emotional ties, and which is precisely constructed during the transaction and circulation of goods and services? Is the unit of analysis the individual, the household, the extended family, lineage, clan or even something else? Should we focus on the urgency of everyday life and the life cycle of an individual or a household, or on the long term that connects past, present and future generations and allows, whatever happens, for the social group to reproduce itself, and simply for life to continue?

Here, our analysis confirms how misleading judgments are on the poor's irrationality and inability to save and calculate. Prudence and sound planning are not restricted to individual behavior, translatable into figures: they must be understood as a composite, as a whole array of relational practices stretching across time and space, using embodied techniques of accounting and memory that anchor these practices in social relations, in time and in space. And the underlying logic cannot be confined to daily survival or production. It is a question of social reproduction over time, and of households, communities and generations situated within specific spaces.

One might believe relational and reproductive saving to be limited to exotic populations, excluded from western modernity. Yet it seems that in the global North, too, saving circuits and calculations practices among the poor escape from the control of reformers, bankers and social workers (Perrin-Herredia 2013; Snow et al. 2016). Just because the rich, by and large, intensively use banking services does not mean that they escape the constraints of social reproduction: it is just that their social reproduction is partly based on accumulation logics, to which banking finance contributes intensively, while also being embedded within complex, sophisticated social bonds (Ho, 2009).

One may then questions the performativity of saving products that are offered or sometime imposed. Asserting that the poor lack self-control, a sense of time or the discipline to resist social pressure is not just bias towards complex realities. It also ignores the crucial role of social interdependencies in individual agencies, subject formation and the fabric of identities. Ever since development policies have emerged, they have been imbued with the economic ethos and considered target populations as economic individuals and not as social beings. But these social beings resist, transform, manipulate, 
2019.Guérin I. Kumar S. Venkatasubramanian G. Relational and reproductive saving: The case of ceremonial expenses in southern India, The Journal of Cultural Economy. https://www.tandfonline.com/doi/full/10.1080/17530350.2019.1583594

transgress or reject the services offered to them. In this instance, the very low level of bank savings attests, at least for the time being, to their lack of appeal. People prefer to create value - and save - by investing in their social networks rather than locking their assets in a bank account. Bank saving is seen as something that may dispossesses them of control over their wealth: bank saving mediates and circulates wealth, but to the service of social groups, entities, temporalities, spaces and objectives that elude poor savers.

Controlling the poor through finance and money is of course nothing new (Zelizer 1994). New technologies, however, have allowed to expand the frontiers of financial inclusion even further. Remote spaces and populations, which have long been considered "unbankable", are now seen as the markets of the future, and this is particularly true in India (Kar 2017). The combination of "technology solutionism" and behavioural finance, together with the dream of a cashless economy, has given rise to a wide range of artefacts, techniques and devices that are supposed to help the poor better manage their finances. It is sometimes possible to resist this drive, as is the case here, but financial inclusion is sometimes achieved through force, as was the case with the 2016 Indian demonetization, forcing the entire population to deposit their monetary assets in a bank account to avoid losing their value (Guérin et al. 2017).

Understanding local values and practices does not mean that they should be romanticized. So-called informal and endogenous ceremonial saving practices are governed by norms and values that are fundamentally hierarchical, for example in terms of gender (the dowry is the most severe expression) or in terms of caste and class (due to practices of imitation and replication of Brahmanic and upper-class rituals). Our purpose is simply to reflect on the underlying logic, processes and universes of meaning that guide value storage and circulation practices, and to emphasize the perils of ignoring them. Unlike what most financial services promoters and the economists who advise them think, money and finance are not just technologies: they are "an extension of relationships, between ourselves and others, our past and futures, our world, and the world we can imagine" (Maurer 2015: 143). Designing financial services is not a neutral exercise: it underlies a certain type of society. At the same time, anthropology is not about designing fairer and more equitable financial services, but to make intelligible the moral universes 
2019.Guérin I. Kumar S. Venkatasubramanian G. Relational and reproductive saving: The case of ceremonial expenses in southern India, The Journal of Cultural Economy. https:/ / www.tandfonline.com/doi/full/10.1080/17530350.2019.1583594

that animate both the promoters of the services and their users, their irreconcilability but also their asymmetry, since local people's voices are rarely heard.

\section{List of references}

Banerjee A., Duflo E., (2011), Poor Economics. A Radical Rethinking of the Way to Fight Global Poverty, New York : Public Affairs, ix-303 p.

Berry S. (1989) Social institutions and access to resources, Africa, LIX: 41-55.

Bloch M, and J. Parry (1989) (eds) Money and the Morality of Exchange, Cambridge University Press: Cambridge.

Cattelino J. (2009) Fungibility: Florida Seminole Casino Dividends and the Fiscal Politics of Indigeneity, American Anthropologist, 111(2): 190-200.

Cederlof G. (1997 Bonds Lost; Subordination, Conflict and Mobilisation in Rural South India c.. 19001970, New Delhi: Manohar.

Collins D, Morduch J, Rutherford S, Ruthven O. (2009) Portfolios of the Poor: How the World's Poor Live on $\$ 2$ a Day. Princeton University Press: Princeton.

De Neve G. (2000) Patronage and 'community': the role of a Tamil 'village' festival in the integration of a town. Journal of the Royal Anthropological Institute, 6 (3). 501 - 519.

Dowdy S. M. (2014) How “The Poor” Account Financial Reckoning and its Cosmoeconomics in Assam, India, IMTFI report.

Douglas M., Isherwood B. C. (1980) The Worlds of Goods, Harmondsworth: Penguin Books.

Goedecke J. Guérin I., D’Espallier B.,Venkatasubramanian G. (2018) Why do financial inclusion polities fail in mobilizing savings from the poor? The social and cultural regulation of saving in rural India, Development Policy Review, 36(S1): 0201-0219.

Guérin I. Villarreal, M. Kumar S. (2018) Carola and Saraswathi: Juggling Wealth in India and in Mexico in Maurer B., Musaraj S., Small I. (eds) Money at the margins. Global Perspectives on Technology, Financial Inclusion and Design, New-York: Berghahn, pp 102-123.

Guérin I., Lanos Y., Michiels S., Nordman J. Venkatasubramanian G. (2017) Insights on demonetization from Rural Tamil Nadu, Understanding social networks and social protection, Economic and Political Weekly, 52(52), 30 Dec 2017, 44-53.

Guyer, J. (1997) Endowments and assets: the anthropology of wealth and the economics of intrahousehold allocation, in L. Haddad, J. Hoddinott, and H. Alderman (eds) Intrahousehold Resource Allocation in Developing Countries: Methods, Models, and Policy. Baltimore, MD: Johns Hopkins University Press.

Hindu Business Line (2014) End financial untouchability for freedom from poverty: PM, Published on 28 August.

Ho K. (2009) Liquidated: An ethnography of Wall Street. Durham, NC: Duke University Press.

Joseph N. (2018) The socio-politics of producing silk and accumulating gold in a South Indian town through the liberalisation reform period, PhD Thesis, EHESS, Paris.

Kar S. (2017) Relative indemnity: risk, insurance, and kinship in Indian microfinance, Journal of the Royal Anthropological Institute, 23(2): 302-319. 
2019.Guérin I. Kumar S. Venkatasubramanian G. Relational and reproductive saving: The case of ceremonial expenses in southern India, The Journal of Cultural Economy. https:/ / www.tandfonline.com/doi/full/10.1080/17530350.2019.1583594

Karlan, D., Ratan, A. L. and Zinman, J. (2014) Savings by and for the Poor: A Research Review and Agenda. Review of Income and Wealth, 60: 36-78.

Kapadia, K.. (1996) Siva and her Sisters. Gender, Caste and Class in Rural South India, New Delhi : Oxford University Press.

Lazarus J. (2016) The issue of financial literacy: Low finance between risk and morality, Economic Sociology-The European Electronic Newsletter, 17(3): 17-34.

Malinowski B. (1961) Argonauts of the Western Pacific: An Account of Native Enterprise and Adventure in the Archipelagoes of Melanesian New Guinea. New York: Dutton [1st edition 1922].

Maurer B. (2015) How would you like to pay? How Technology is Changing the Future of Money. Durham and London: Duke University Press.

Mauss M. (1993) Essai sur le don in Mauss, Sociologie et anthropologie, Paris : PUF [1st edition 1950], pp. 145-272.

Morduch J. (1999) Between the State and the Market: Can Informal Insurance Patch the Safety Net?, The World Bank Research Observer, 14(2): 187-207.

Morvant-Roux S. \& Servet J-M. (2014) Disgression on the relations between anthropology and economics on the topic of 'primitive' moneys. A page in the history of thought, In Allisson F. \& Baranzini R. (eds.) Under the oak's shade. Festschrift in Honour of Pascal Bridel, PICKERING \& CHATTO, pp. 213-223.

Narotzky, S., \& Besnier, N. (2014) Crisis, Value, and Hope: Rethinking the Economy: An Introduction to Supplement 9. Current Anthropology, 55(S9), S4-S16.

Parry J. (1989) On the moral perils of exchange, in Bloch \& Parry (eds) Money and the Morality of Exchange, Cambridge University Press: Cambridge, pp. 64-93.

Peebles P. (2014) Rehabilitating the Hoard: The Social Dynamics of Unbanking in Africa and Beyond, Africa. 84(4): 595-613.

Perrin-Heredia A. (2013) La mise en ordre de l'économie domestique. Accompagnement budgétaire et étiquetage de la déviance économique, Gouvernement et action publique 2(2) : 303-330.

Picherit D. (2018) Rural Youth and Circulating Labour in South India: The Tortuous Paths Towards Respect for Madigas. Journal of Agrarian Change, 18: 178-195.

Polanyi K. (1977) The livelihood of man, New-York: Academic Press.

Pouchepadass J. (1980) L’endettement paysan dans le Bihar colonial, Purusartha, nº4, pp. 165-206.

Saiag H. (2013) Financial practices as adaptations to increasing vulnerability in A. Lemaître, I. Hillenkamp et F. Lapeyre (eds.), Securing Livelihoods : Informal Economy Practices and Institutions, Oxford et New-York : Oxford University Press, pp. 99-114.

Shipton P. (2007) The Nature of Entrustment. Intimacy, Exchange and the Sacred in Africa. New-Haven \& London: Yale University Press.

Snow S., Vyas D. \& Margot Brereton M. (2016) Sharing, Saving, and Living Well on Less: Supporting Social Connectedness to Mitigate Financial Hardship, International Journal of Human-Computer Interaction, 33(5): 345-356.

Rao V. (2001) Celebrations as Social Investments: Festival Expenditures, Unit Price Variation and Social Status in Rural India, Journal of Development Studies, 38:1: 71-97. 
2019.Guérin I. Kumar S. Venkatasubramanian G. Relational and reproductive saving: The case of ceremonial expenses in southern India, The Journal of Cultural Economy. https://www.tandfonline.com/doi/full/10.1080/17530350.2019.1583594

Reserve Bank of India (RBI) (2013) 'Financial Inclusion: an Assessment'. New-Delhi. Available at: http://rbidocs.rbi.org.in/rdocs/Speeches/PDFs/MFI101213FS.pdf (accessed March 23, 2015).

Rosenzweig, M. R. (2001) 'Savings behaviour in low-income countries', Oxford Review of Economic Policy 17(1), 40-54.

Rutherford, S. (2001) The Poor and Their Money. Oxford: Oxford University Press.

Yates F. (1966) The arts of memory, Chicago: Chicago University Press.

Zelizer V. (1994) The social meaning of money, New-York: Basic Books.

Zelizer V. (2012) How I became a relational economic sociologist and what does that mean? Politics \& Society, 40(2): 145-174. 
2019.Guérin I. Kumar S. Venkatasubramanian G. Relational and reproductive saving: The case of ceremonial expenses in southern India, The Journal of Cultural Economy. https://www.tandfonline.com/doi/full/10.1080/17530350.2019.1583594

\section{Graph. 1. Ceremonies as 'saving up'}

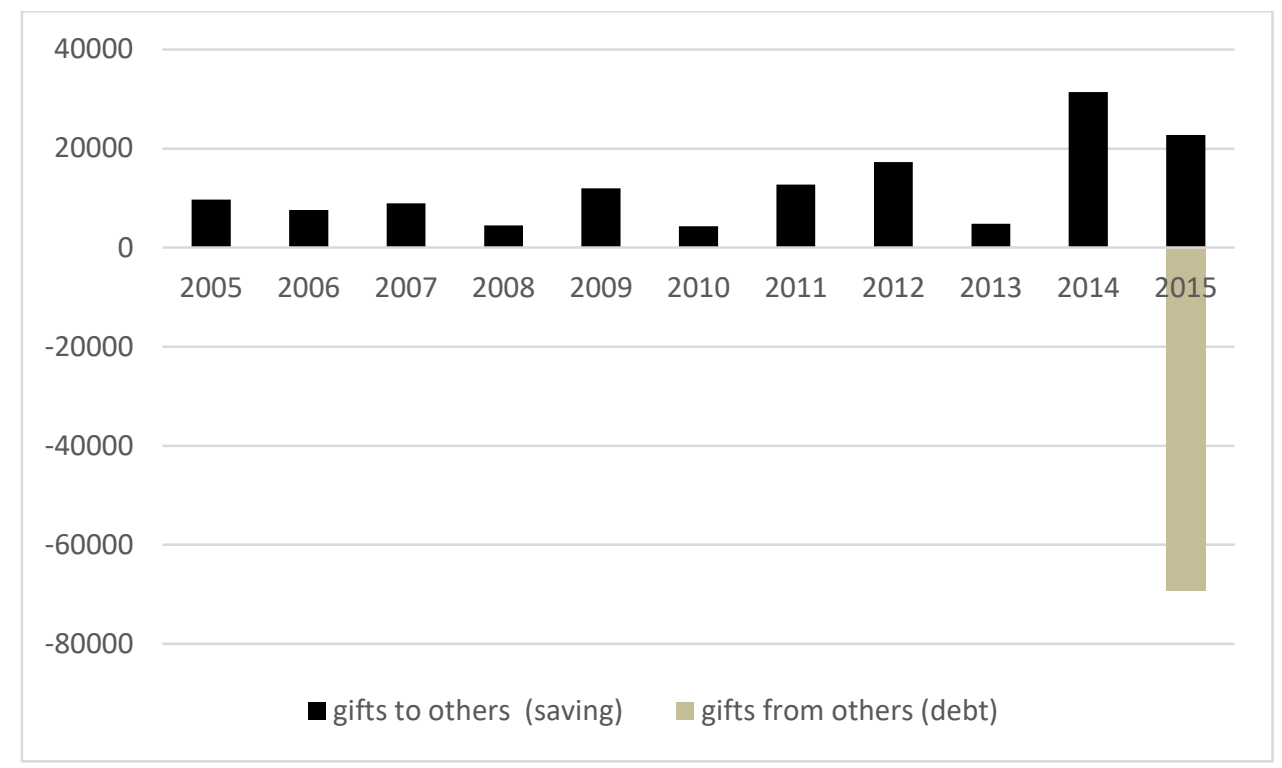

Source: Authors

\section{Graph 2. Gifts given and received (housewarming ceremony)}

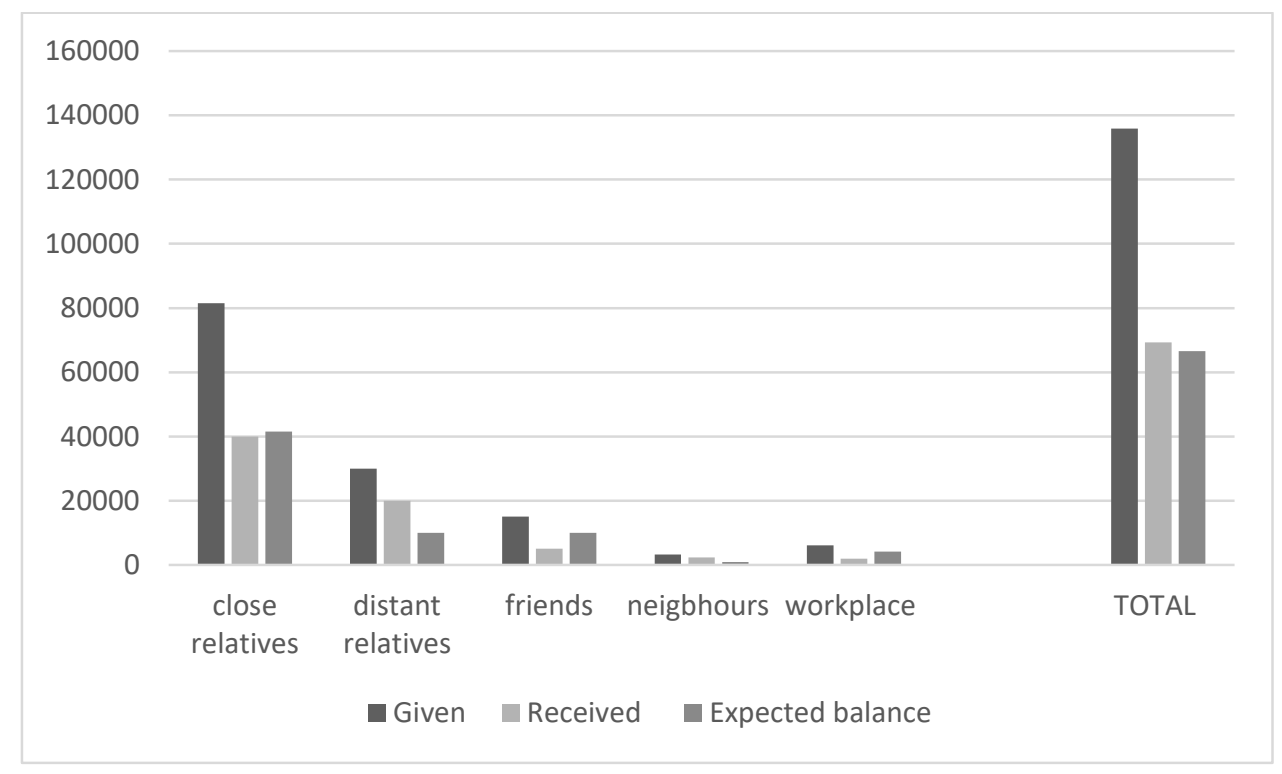

Source: Authors (2016 fieldwork) 
2019.Guérin I. Kumar S. Venkatasubramanian G. Relational and reproductive saving: The case of ceremonial expenses in southern India, The Journal of Cultural Economy. https://www.tandfonline.com/doi/full/10.1080/17530350.2019.1583594 


\section{Photograph 1. A notebook for a puberty ceremony}

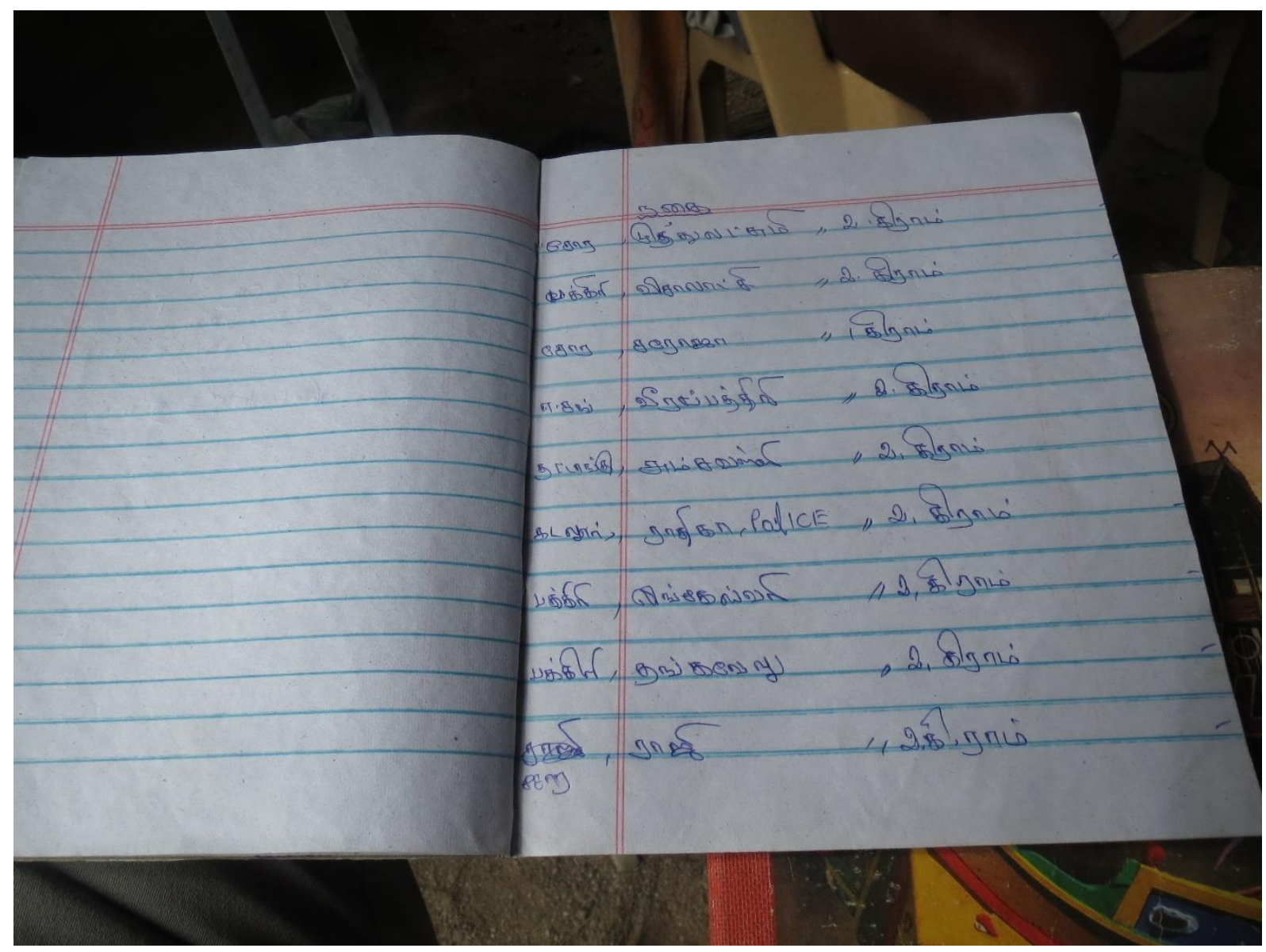

Source: Author, 2015

Photograph 2. A notebook for a housewarming 


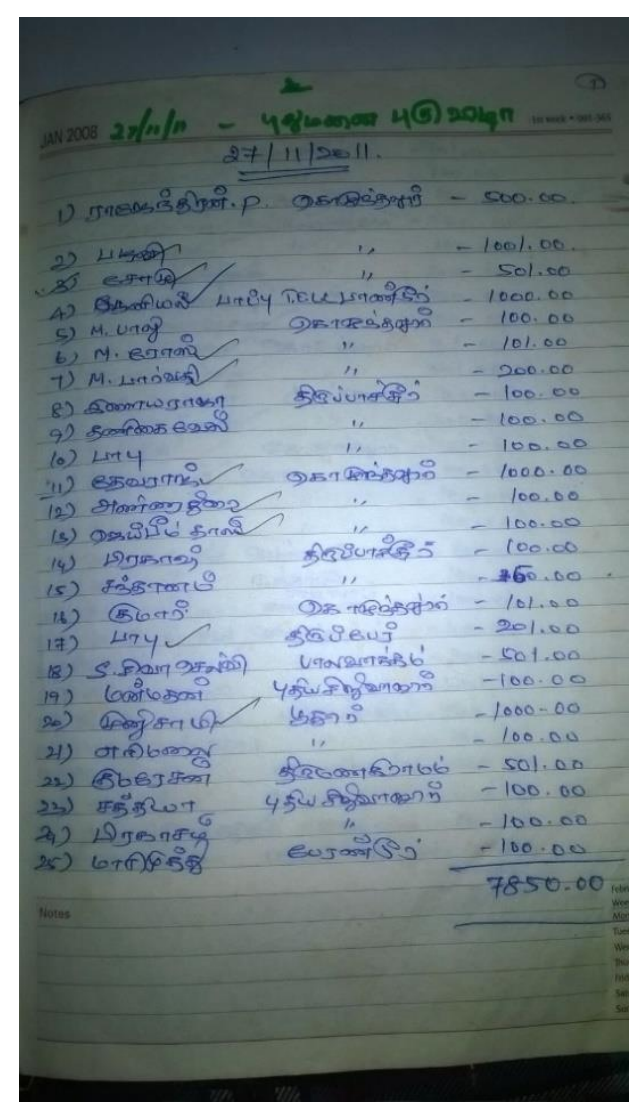

Source: Author, 2015 